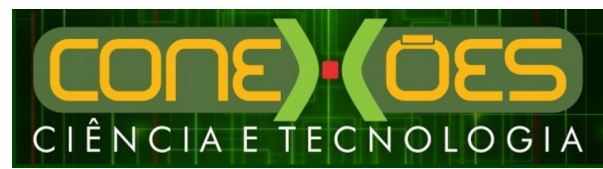

\title{
UMA ANÁLISE DO DESENVOLVIMENTO DOS BARCOS SOLARES
}

\author{
Mauricio Aguilar Nepomuceno de Oliveira ${ }^{1}$, Walter Issamu Suemitsu ${ }^{1}$ \\ ${ }^{1}$ Universidade Federal do Rio de Janeiro \\ <mauricio.a.n.oliveira@gmail.com>. <walter@dee.ufrj.br>
}

DOI: $10.21439 /$ conexoes.v11i3.897

\begin{abstract}
Resumo. Em virtude do aumento da poluição nas grandes cidades, os meios de transporte de emissão zero estão sendo amplamente discutidos. Um exemplo importante são os barcos solares, porém essas embarcações existem em uma proporção muito pequena comparada aos barcos movidos por combustíveis fósseis. A fim de entender porque esses barcos ainda não dominaram o mercado, este trabalho tem o objetivo de fazer uma análise do desenvolvimento histórico dos barcos solares. Atualmente os barcos solares são definidos como embarcações que utilizam um motor elétrico abastecido por energia elétrica proveniente da conversão da energia solar por painéis fotovoltaicos. A energia elétrica convertida pode ser armazenada em baterias ou não. Para se entender o histórico dessas embarcações é necessário entender o desenvolvimento dos painéis solares, dos motores elétricos e das baterias, e obviamente das embarcações. Para realizar esta análise fez-se uma revisão bibliográfica da história do desenvolvimento das embarcações e da eletricidade, e analisou-se como esse desenvolvimento resultou nos primeiros barcos solares encontrados. Depois mapeou-se os barcos solares existentes a partir do trabalho do pesquisador holandês Tim Gorter e analisou-se algumas características importantes dos motores, baterias, controladores e painéis fotovoltaicos utilizados em embarcações solares.
\end{abstract}

Palavras-chaves: Barcos solares. Energias renováveis. Histórico. Veículos elétricos. Emissão zero.

Abstract. Due to the increasing pollution in large cities, the zero-emission vehicles are being widely discussed. An important example are the solar boats, but these vessels exist in a very small proportion compared to the boats powered by fuel. In order to understand why these boats did not dominate the market, this work aims to make an analysis of the historical development of solar boats. Nowadays one defines solar boats as vessels that use an electric motor supplied by electricity from the conversion of solar energy by photovoltaic panels. The converted electrical energy can be stored in batteries or not. To understand the history of these vessels, it is necessary to understand the development of the solar panels, electric motors and batteries, and obviously vessels. To do this analysis we have done a literature review of the historical development of vessels and electricity and we analyzed how this development resulted on the first solar boats found. After existing solar boats were analyzed, from the work of the Dutch researcher Tim Gorter, along with some important features of motors, batteries, controllers and photovoltaic panels used in solar boats.

Keywords: Solar boats. Renewable energy. Historical. Electric vehicles. Zero emission. 


\section{INTRODUÇÃO}

No passado não havia o conceito ambiental na palavra desenvolvimento, porém hoje, ao pensarmos em desenvolvimento pensamos na melhoria da qualidade de vida e deveríamos pensar na valorização do meio ambiente, pois a ele estamos diretamente ligados e dele usufruímos. Em nossas posturas e atos, revendo nossos conceitos, percebemos que produzimos muitos resíduos e não nos preocupamos com o seu destino, destacando, neste trabalho, os gases emitidos em nossos processos industriais e em nossos veículos. Devido ao enorme aumento dos gases emitidos pelos mais variados meios de transporte, podemos observar em uma escala local uma nuvem de fumaça e poeira cobrindo os centros urbanos, em uma escala regional as chuvas ácidas e em escala global identifica-se que o planeta está aquecendo, causando o aumento do efeito estufa (SAMPAIO, 2006). Sendo assim, temos que parar para pensar onde vamos chegar se não mudarmos nossas posturas e adotarmos a palavra sustentável junto à palavra desenvolvimento. Porém, para alcançar esse objetivo, a sociedade não pretende voltar a sua era primitiva, e, portanto, as necessidades de transporte devem ser atendidas. Dentro desse contexto, que alternativas sustentáveis a sociedade tem para continuar se locomovendo sem emitir gases poluentes?

Uma alternativa para reduzir os impactos listados acima é o desenvolvimento de veículos elétricos. Dentre os veículos elétricos destacam-se os veículos solares, pois não emitem $\mathrm{CO}^{2}$ na atmosfera. Segundo Oliveira (2013), as embarcações solares são viáveis para o transporte de passageiros, embora mais lentas, sendo capazes de cumprir o seu propósito com retorno econômico. Porém Gorter et al. (2010), em vasta pesquisa ao redor do mundo, levantou 162 embarcações solares no planeta. Este número é inexpressivo comparado ao número de embarcações existentes movidas por combustíveis fósseis.

A fim de pesquisar a causa desta situação, este trabalho tem o objetivo de analisar o percurso histórico dos barcos solares e realizar uma análise dos barcos solares existentes, seus motores, painéis e baterias. O método para fazer essa investigação foi a consulta a referencial bibliográfico de artigos de outros autores e a uma base de dados dos barcos solares existentes, do pesquisador Tim GORTER.

A primeira referência a um barco solar foi feita na revista Science de 16 de março de 1965 (WALSH. 1965). Porém, para surgir o primeiro barco solar foi necessário surgirem os painéis fotovoltaicos, as baterias, os motores elétricos e, obviamente, os barcos. Os barcos têm uma história tão longa que se confunde com a da própria humanidade. A eletricidade, que governa o desenvolvimento dos painéis, motores e baterias tem uma complexidade no seu desenvolvimento histórico que refletir sobre ela poderia envolver um trabalho inteiro. Porém, para pensarmos com mais clareza o desenvolvimento dos barcos solares, considera-se primeiro entender, mesmo que de maneira breve e pontual, essas descobertas.

Primeiro será realizada uma passagem rápida sobre o percurso de desenvolvimento da eletricidade, enfocando as descobertas que proporcionaram o surgimento das baterias, motores e painéis fotovoltaicos. Ao fim será feita uma breve discussão sobre a história do uso da energia nas embarcações, tendo em vista que o que mais interessa sobre a história das embarcações é como estas utilizavam a energia.

Segundo será feita uma descrição dos barcos solares existentes e uma descrição dos principais motores, bateria, controladores e painéis fotovoltaicos a serem utilizados e algumas características relevantes para os barcos solares.

\section{HISTÓRICO DOS BARCOS SOLARES}

\subsection{Primeiro Ciclo: descobrimento da eletricidade, da pilha e do primeiro motor.}

Os primeiros estudos ligados à eletricidade são os de eletrostática, iniciados em 250 a.C. A eletricidade como fonte de pesquisa surge no século XVIII (POMILIO, 2011). O interesse dos cientistas pela eletricidade desperta com os experimentos do italiano Luigi Galvani, em 1780. Alessandro Volta, também italiano, descobre a corrente contínua e a primeira pilha. A pilha de Alessandro Volta era formada por prata e zinco, separados por panos umedecidos em sal ou ácido fraco. As placas de metais eram empilhadas, por isso o nome de pilha (NISENBAUM, 2008).

O desenvolvimento da pilha permitiu inúmeros avanços, entre eles o surgimento do campo de estudo da eletroquímica, que é a base para o desenvolvimento das baterias e dos painéis fotovoltaicos, e por isso pode ser considerado o primeiro e mais significativo desenvolvimento para os barcos solares. Em 1831, o britânico Faraday inicia o estudo do eletromagnetismo essencial para o desenvolvimento dos motores elétricos. O desenvolvimento do primeiro motor de Corrente Continua (CC) se inicia em 1832 com o Inglês William Sturgeon, seguido pelos americanos Emily e Thomas Davenport que, em 1837, chegam ao primeiro motor CC com comutador. Porém, as pilhas não forneciam energia suficiente para o motor funcionar, inviabilizando o seu uso (POMILIO, 2011). O alemão Mortiz, residindo na Rússia, desenvolve também um motor elétrico, em 1834. 
Em paralelo ao surgimento do motor, o desenvolvimento das pilhas prosseguiu, com o objetivo de aumentar suas potências. O britânico Daniel desenvolve, em 1836, uma pilha composta por 2 eletrólitos, e com isso aumenta a potência da mesma. Os metais utilizados por ele são zinco e cobre em soluções de $\mathrm{Cu}^{2+} \mathrm{e}$ $\mathrm{Zn}^{2+}$ (NISENBAUM, 2008). Por conta dos estudos em eletroquímica, o francês Becquerel observa, em 1839, que duas placas metálicas de platina ou prata quando expostas à luz produziam uma pequena diferença de potencial, e então é observado pela primeira vez o efeito fotovoltaico (VALLÊRA; BRITO, 2006).

O primeiro ciclo de desenvolvimento de três artefatos essenciais da embarcação solar foi fechado: temse uma bateria, um motor e a geração de diferença de potencial pela luz solar. Porém, o efeito fotovoltaico observado produz uma diferença de potencial muito pequena e, portanto, não garante a alimentação dos motores. Assim, o uso da energia solar ainda não é uma realidade. Todavia, observa-se por volta de 1840 o surgimento do primeiro barco elétrico criado por Moritz, em São Petersburgo, na Rússia. O barco de Moritz apresenta algumas dificuldades durante a sua navegação, já que a tripulação fica intoxicada pelos vapores provenientes da pilha. O barco alcançou, em 1840, três milhas por hora com 12 passageiros (HAWTHORNE, 1998).

\subsection{Segundo Ciclo: bateria de chumbo ácido, mo- tor CC e efeito fotovoltaico.}

Em 1839 o britânico Wiliam Groove desenvolve a célula de combustível, também conhecida como célula de hidrogênio, uma grande mudança para as pilhas existentes pois, até então, quando as pilhas emitiam toda a sua energia estas se tornavam inúteis e deveriam ser fabricadas novas pilhas. A célula de combustível de Groove era alimentada por dois combustíveis: o hidrogênio e o oxigênio. Esta célula não produzia voltagem suficiente para utilização prática e sua tecnologia teve que aguardar até 1960 para voltar a ser discutida (NISENBAUM 2008).

Percebe-se que existia uma busca por produzir mais energia. Em 1859 o francês Gaston Plante desenvolve a bateria de chumbo ácido. Esta bateria é utilizada amplamente até os dias de hoje, porém atualmente não funciona da mesma forma que foi criada por Plante, já que incorporou inúmeras inovações no século XX. A grande inovação proposta pelas baterias de chumbo ácido de Plante foi a possibilidade de ser recarregada (NISENBAUM, 2008). Porém, como não existiam fontes energéticas que permitissem que ela fosse recarregada, essas baterias só conheceram essas utilizações práticas com o surgimento dos dínamos (CHAGAS, 2007).
Em 1873 o belga Gramme inventa o dínamo CC, que, acionado por uma máquina a vapor, produzia eletricidade. Em 1877 inventores norte-americanos utilizam o selênio para produzir fotômetros de máquinas fotográficas, resgatando as pesquisas de Becquerel (VALLÊRA; BRITO, 2006).

Observa-se que no fim do século XIX temos o primeiro motor CC funcionado com uma estrutura muito próxima da que opera nos dias de hoje (2015), mas com mecanismos de controle da velocidade simples e ineficientes. Também já existia uma bateria razoável, a mesma bateria de chumbo ácido utilizada nos dias de hoje, porém ainda não eram seladas e necessitavam de reposição de eletrólito. Havia também um aproveitamento do efeito fotoelétrico, que apesar de desprezível para a recarga das baterias, já era comercializável em máquinas fotográficas, mas a energia solar ainda vai aguardar as descobertas do século XX para se desenvolver. O motor CC e a bateria sofrerão modificações, mas essencialmente já foram inventadas. Com isso, no fim do século XIX começam a surgir muitos barcos elétricos e em 1892 surge uma empresa que os comercializa, como mostra o anúncio abaixo (HAWTHORNE, 1998).

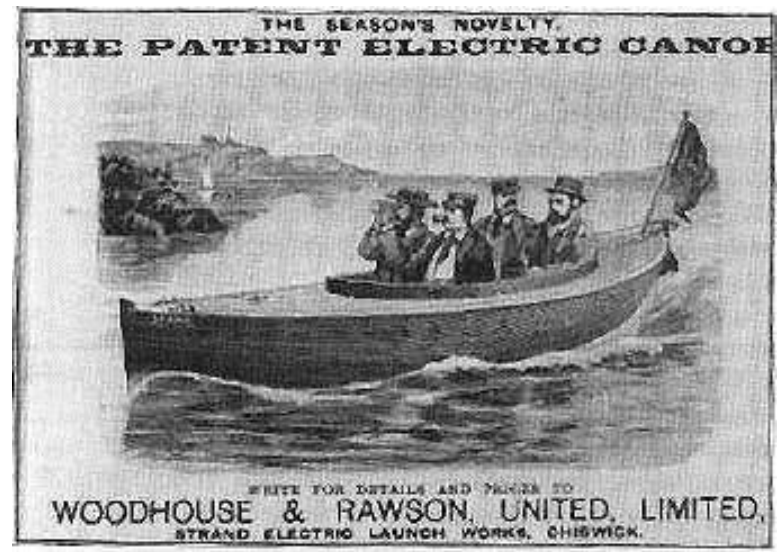

Figura 1: Anúncio de barcos elétricos. Fonte: HAWTHORNE. 1998).

Segundo Hawthorne (1998), por volta de 1890 existia um grande número de barcos elétricos navegando no rio Tâmisa, algo em torno de 120 embarcações. Para reabastecer as baterias existiam três pontos de recarga fixos e dois flutuantes. O maior de todos os barcos elétricos daquela época foi o Viscountess Bury, de 65 pés que carregava 80 passageiros. Este barco foi convertido num motor a óleo em 1910. Em 1930 os barcos elétricos somem do rio Tâmisa (HAWTHORNE, 1998). É interessante observar como outros veículos elétricos surgem nessa mesma época. Em 1868 surgem os metrôs movidos inicialmente por máquinas a vapor, porém 
a fumaça nos túneis se torna insuportável e os motores elétricos são adotados. Em 1890 os motores elétricos já eram amplamente utilizados (SLOCOMBE, 2007 apud WIKIPEDIA). Esses dados mostram que os motores elétricos foram maioria na locomoção de veículos no fim do século XIX. Voltaremos a discutir o caso dos carros elétricos mais à frente.

\subsection{Terceiro Ciclo - Corrente Alternada, Painéis So- lares e Eletrônica de Potência}

Para que os motores elétricos seguissem se desenvolvendo, a descoberta da corrente alternada e a popularização da eletricidade são desenvolvimentos importantes, que ocorrem em um momento histórico que se inicia com o invento da lâmpada pelo norte americano Thomas Edison, em 1879. Tesla desenvolve em 1888 o motor de indução e dá inicio ao surgimento da corrente alternada. Edison e Tesla iniciam uma guerra, chamada de "guerra das correntes" ou "guerra elétrica", para saber qual seria o melhor sistema para alimentar a iluminação pública, se a corrente contínua ou alternada. Com o surgimento do motor de indução e a rápida comprovação de sua alta eficiência na produção de energia, a "vitória" é de Tesla e da corrente alternada. Cria-se um panorama para a popularização da eletricidade, ampliando rapidamente as redes de iluminação pública em corrente alternada (CA). Entretanto, os motores CA recém desenvolvidos não possuíam um sistema de controle de velocidade e, para utilizações nas quais o controle de rotação era crucial, ainda se utilizavam os motores CC. Toda a energia era gerada e consumida em corrente alternada, mas os motores continuavam operando em corrente contínua. Ao menos as baterias já podiam ser recarregadas por dínamos CC. Era necessário, entretanto, possuir um gerador de $\mathrm{CC}$ apenas para esses motores, aumentando o gasto de capital. Eis que em 1904 Flemming, a partir de experiências de Edison com as lâmpadas, cria o diodo com dois polos, que se trata de uma lâmpada que retificava a corrente. O dispositivo consistia de dois polos, sendo que ao primeiro polo era conectada a corrente alternada. Quando a carga dessa corrente era positiva ela emitia um elétron, que era recebido pelo outro polo (eletrodo) da lâmpada, e quando era negativa nada acontecia. Assim a corrente foi retificada. Porém, como o interior do diodo de Flemming era a vácuo, este permitia uma pequena capacidade de condução de corrente; assim, os geradores CC ainda eram utilizados (POMILIO, 2011).

Em 1947 John Bardeen e Walter Brattain, trabalhando no Bells Lab, estudavam o comportamento de um elétron na interface de um metal e um semicondutor. Ao fazer um contato muito próximo um do outro criaram um dispositivo de 3 terminais, o transistor. Este material sólido parecia, de início, vir para substituir as válvulas até então amplamente utilizadas na retificação de sinais. Os primeiros transistores eram construídos em germânio, e ao longo da década de 50 foram substituídos pelo silício (POMILIO, 2011). Porém, esse desenvolvimento vai além dos retificadores de corrente e cria uma nova eletrônica que será discutida mais à frente. Apesar da eletrônica ter iniciado suas pesquisas com as válvulas, a ampliação das possibilidades pela redução dos tamanhos dá outra dimensão a esse campo de estudos.

Vallêra e Brito (2006), descrevem o desenvolvimento das células fotovoltaicas. As primeiras células solares estudadas eram de selênio e possuíam uma eficiência de $1 \%$. Os trabalhos desenvolvidos desde então, tiveram o objetivo de aumentar a eficiência das células, e para isso foram pesquisados diferentes materiais e técnicas de montagem.

Em 1960 surge uma empresa para comercializar os painéis fotovoltaicos. O comércio era realizado apenas para boias de navegação, ou para geração de energia para regiões muito remotas. Porém, em 1973 o preço do petróleo quadruplicou e foram criados programas para reduzir os custos de produção das células solares. Foi trocado o silício monocristalino pelo policristalino, a fim de reduzir os custos. Depois foram realizados estudos para permitir a fabricação do silício em camadas finas, evitando os altos custos de cortar grandes blocos do material. Outra técnica foi a troca da disposição de contatos, anteriormente feita por fotolitografia ou por deposição, por evaporação em vácuo pela serigrafia dos contatos. Essas alterações acarretaram uma redução de custo dos anteriormente $80 \$ / W$ para $12 \$ / W$. As células continuaram avançando em termos de eficiência e na década de 70 ultrapassou-se a barreira dos $20 \%$ de eficiência nas células de silício monocristalino, na Austrália, e 25\% com concentradores de luz (VALLÊRA; BRITO, 2006).

Em 1982 surge na Califórnia a primeira central solar de grande envergadura, com 1 MW. Surge também o programa de telhados solares na Alemanha e no Japão, em 1990. Estes programas aparecem devido ao indicativo de que seria necessário um ganho de escala para o desenvolvimento dos painéis solares.

O desenvolvimento dos painéis solares a partir da década de 1950 fecha um ciclo que faltava para os barcos solares. Pode-se perceber que a primeira empresa a comercializar painéis surge na década de 1960, e o primeiro barco citado data de 1965. Durante esses anos, outros desenvolvimentos surgiram, e o mais importante deles foram no campo da eletrônica, permitindo o con- 
trole de velocidade dos motores CA, por meio de conversores de CC para CA, denominados inversores. Para entender esse avanço, volta-se ao inicio do surgimento dos painéis solares.

Pode-se observar que após o surgimento do primeiro motor CA surge a dificuldade de controlar a sua velocidade. O processo de controle realizado nos motores CC era fácil, porém muito pouco eficiente. Com o surgimento do campo da eletrônica de potência pelos transistores, tiristores e os IGBTs (Insulated Gate Bipolar Transistors), surgem inúmeros mecanismos eletrônicos de controle da velocidade e intensifica-se o desenvolvimento de inversores. Os motores CA podem ser incorporados em veículos de tração ou em máquinas que necessitem de controle de velocidade, e os de CC ganham sistemas de controle mais eficientes. A eletrônica possibilita o surgimento do MPPT (Maximum Power Point Tracker) e dos controladores de carga para os painéis solares.

As baterias de lítio surgem na década de 1970, porém as primeiras pesquisas que utilizam lítio como eletrodo são de 1912, por GN Lewis (NISENBAUM. 2008) sendo que a primeira bateria de lítio comercializável data de 1990, fabricada pela Sony.

A partir desse breve histórico dos três artefatos que compõem a embarcação solar, considera-se importante observar como as embarcações utilizavam a energia para sua locomoção. Percebe-se que as bases materiais para a utilização dos barcos elétricos existem desde o fim do século XIX, chegando a existir em alguns momentos uma frota considerável no rio Tâmisa. Entretanto, o aspecto econômico levou os barcos elétricos a serem substituídos, já que barcos a vapor possuíam maior velocidade e autonomia.

No fim do século XX as condições materiais estão completas para o desenvolvimento dos barcos solares. Os módulos fotovoltaicos são uma realidade e completam um ciclo que permite seus desenvolvimentos. Na mesma época surgem alguns protótipos de barcos solares, porém não ganham espaço de mercado. Por que? Antes de responder a essa pergunta, cabe observar como foram essas substituições das energias para a locomoção das embarcações. Faremos uma breve passagem histórica, com olhos sobre a afirmação de Amorim (1997): “o conhecimento e a técnica são umas das partes essenciais da base material para uma determinada transformação social, a outra é a necessidade econômica". O conhecimento existe, mas é necessário verificar os aspectos econômicos para esse novo produto. Pretende-se observar qual foi a história do uso da energia em embarcações pelo homem, como modificam seus usos e qual a relação que isso tem com a economia.

\subsection{História do uso da energia nas embarcações}

Não se sabe quais foram as primeiras embarcações. Especula-se sobre as canoas de tronco escavado e as jangadas, que apareceram em diversos lugares do mundo com o conceito muito próximo, em alguns casos objetos de flutuação propelidos pela força humana. Comentaremos rapidamente algumas embarcações históricas que possuem registros, para que se possa imaginar esse uso da energia.

Os fenícios navegaram e dominaram os mares de 1500 a.C. até o ano 0 e possuíam embarcações a vela e remo. Existiam barcos que utilizavam apenas a vela, e estes eram utilizados para transporte de carga. Os gregos também possuíam em suas principais embarcações a energia de velas e remos. Os romanos aperfeiçoaram as embarcações gregas e dominaram a Europa até 476 d.C. Assim como os fenícios, os barcos mercantes eram propelidos apenas a vela. Depois de 1400 surge o Cog, que dá origem aos barcos portugueses que iniciam as grandes navegações e expandem o seu conceito de embarcação, que dominou primeiro a Europa e depois se estendeu a boa parte do planeta. O Cog era propelido apenas pela energia do vento (AMORIM, 1997).

A energia do vento predomina até a revolução industrial, quando surgem as máquinas a vapor que rapidamente são apropriadas para as embarcações. Em 1785 Jonathan Hulls cria um rebocador a vapor. Predominavam as rodas de madeira para tração. Os hélices se estabeleceram apenas em 1860 (DATHEIN, 2003).

Em virtude da baixa eficiência das máquinas a vapor, que demandavam imensos espaços no porão para carregar carvão, os barcos a vapor possuíam menos espaço de carga, um custo maior e a mesma velocidade final. Logo os barcos a vela seguiam dominando as rotas e convivendo com os barcos a vapor por muitos anos. Em determinado período se tornaram híbridos, possuindo máquinas a vapor e aparelho vélico. Para ilustrar o convívio dos barcos a vapor e a vela, analisamse os números de HOBSBAWN apud DATHEIN, 2003, que mostram a produção de barcos a vapor e a vela por tonelada ano na Grã-Bretanha. Em 1830 foram produzidas duas toneladas de barcos a vapor e em 1855 chegou-se a 81 mil toneladas. No mesmo ano foram produzidas 810 mil toneladas de porte bruto de embarcações à vela, 10 vezes mais quase 100 anos após seu surgimento. Apenas em 1880 a produção de barcos a vapor ultrapassa a produção de barcos a vela em toneladas. Como comentado anteriormente, os barcos movidos por motores elétricos existem e conviveram, em especial no rio Tâmisa, nessa época.

Um novo período histórico começa a se configurar com o predomínio das máquinas a vapor. A energia 
para a locomoção dessas máquinas provém em especial do carvão. A próxima ruptura importante em relação ao uso da energia surge com os motores de combustão interna.

O primeiro motor de combustão interna que funcionou foi o de Cecil, operava com uma mistura de ar e hidrogênio, Lenoir melhorou este, trabalhando com gás proveniente do carvão, e construiu o primeiro triciclo que deu a volta na Europa, mas que não foi comercializado. Os famosos motores a diesel surgem em 1893 por Diesel (VARELLA, 1995).

Desde o inicio do século XX os navios passam a adotar os motores a diesel. Alguns sítios indicam como pós segunda guerra mundial o predomínio dos motores a diesel nos navios. No Brasil foram encontrados navios a vapor em 1950 em operação como relatado por Aquino (2012). O uso do petróleo apresenta imensas vantagens sobre o carvão, produz o dobro da energia por massa e ocupa metade do volume, além de permitir alimentação mecânica reduzindo a mão de obra. Fica fácil perceber por que o carvão foi substituído mais rapidamente nas embarcações do que nos trens (DATHEIN, 2003) e porque foi substituído mais rapidamente do que os barcos a vela foram pelos a vapor.

A indústria do petróleo se desenvolve um pouco antes em 1859. Olhando os números de CIPOLA apud DATHEIN, 2003, podemos ver a utilização da energia para indústrias e veículos. Obviamente que esses dados são para toda a indústria e não apenas para as embarcações que tiveram o domínio por volta de 1945.

Tabela 1: Consumo de energia nas indústrias e veículo nos séculos XIX e XX.

Consumo de energia nas industrias e veículos (\%)

\begin{tabular}{|c|c|c|c|c|}
\hline Ano & Carvão & Petroleo & $\begin{array}{c}\text { Gás } \\
\text { natural }\end{array}$ & Hidreletrica \\
\hline 1860 & 98 & 2 & & \\
\hline 1900 & 92 & 8 & & \\
\hline 1950 & 57 & 43 & & \\
\hline 1960 & 43 & 33 & & \\
\hline 1970 & 27 & 46 & 21 & 2 \\
\hline
\end{tabular}

Os carros elétricos têm uma primeira aparição por volta de 1834 e chegam ao mercado por volta de 1880 - datas próximas do surgimento e comercialização dos barcos elétricos. Os carros movidos por motores a combustão surgem em 1885. O confronto entre carros elétricos e carros por motores a combustão existiu por alguns anos. Segundo Caruso (2007), foram produzidos em 1900, na cidade de Nova York, 1575 automóveis elétricos contra 936 a gasolina. Em 1899 a revista Scientific American dizia que os motores elétricos eram ideais para veículos, pois não possuíam os dispositivos complicados do vapor, do ar comprimido, o calor, o ruído e a vibração. Porém os preços de venda do carro elétrico eram um pouco superiores. O custo por quilometro também. Sendo a autonomia menor, não havia motivo para continuar investindo neles. O surgimento dos motores de arranque e das baterias seladas acabou por ajudar os carros a combustão a "vencer" essa batalha, pois a dificuldade inicial dos motores a combustão era com a partida dos mesmos (CARUSO, 2007).

Em 2012 os carros elétricos ocupam novamente grande espaço na mídia. Esse espaço em percentual de veículos produzidos ainda é muito pequeno, porém todas as grandes concessionárias estão investindo em possuir projetos e comercializar veículos elétricos. Os motores movidos por hidrocarbonetos dominam hoje quase a totalidade das embarcações comerciais. As exceções são: embarcações de recreio, embarcações miúdas de pesca e esportivas propelidas a vela e remo e os barcos elétricos, que voltam ao cenário em 1975. O impulso são os pequenos motores de popa elétricos para canoas de pescas. As embarcações elétricas conquistam espaço com a crescente perspectiva de redução de impacto ambiental, porém quando se observa a proporcionalidade de barcos elétricos frente à totalidade de embarcações existentes, o impacto atual ainda é inexpressivo.

Os barcos solares surgem em 1975, juntamente com o ressurgimento dos barcos elétricos. O percurso histórico dos barcos solares é muito curto. Depois de 1975 só foram encontrados dados de embarcações solares em 1984, e a partir de então começam a aparecer outros modelos.

\section{ESTADO DA ARTE DO BARCOS SOLARES}

O pesquisador Holandês Tim Gorter vem levantando informações sobre todas as embarcações solares existentes e forneceu a sua base de dados para essa pesquisa. Sua base de dados não está concluída. Os barcos levantados até dezembro de 2012 totalizam 160 embarcações solares únicas. Algumas dessas informações estão disponíveis no artigo: " $P V$-boats: design issues in the realization of $P V$ powered boats', (GORTER et al., 2010).

A fim de entender como são utilizadas essas embarcações, o pesquisador criou quatro grupos de funcionalidade. Os grupos são: transporte de passageiros, pesquisa ou uso privado, recreação e competição. As embarcações de transporte de passageiro têm a funcionalidade de conduzir passageiros de um local a outro. As embarcações de pesquisa são embarcações que não possuem uma finalidade específica, servem apenas para comprovar que uma embarcação é capaz de se movimentar utilizando energia solar. Por esse motivo foi 
agrupada com as embarcações de uso privado, que se referem a proprietários de embarcação que utilizam a sua embarcação a fins de passeio, e logo sua funcionalidade é livre de percursos e de número de passageiros, como os barcos de pesquisa. Os barcos de uso para recreação são barcos alugados para outras pessoas ou para explorar determinado lago ou canal, ou para conhecer a própria embarcação solar, ou no caso mais curioso, o do aquakart, onde são alugados para karts na água. $\mathrm{O}$ ultimo grupo de funcionalidade, os barcos de competição, que ainda são maioria, são destinados a participar de competições de barcos movidos a energia solar, como: a Frisian Solar Challenge e o Desafio Solar Brasil. As embarcações do Desafio Solar Brasil não entraram na contabilidade do pesquisador Tim Gorter. Dezoito embarcações competem no Desafio Solar Brasil, aumentando o número de barcos movidos a energia solar catalogados.

Percebemos que contabilizando os barcos do desafio solar existe uma maioria dos barcos de competição, seguidos pelos barcos de pesquisa e privados em numero semelhantes aos de transporte, indicando que a tecnologia ainda possui um nível experimental, porém a expressão do numero de barcos de passageiros e privados é um indicativo relevante de sua possibilidade de uso nestas funcionalidades.

Os barcos solares não ligados a competição têm como primeira citação o barco solar um barco para pesquisa de uso militar apresentado no artigo de 1965 que sita o desenvolvimento em 1963 onde se comenta da viabilidade para embarcações leves (WALSH, 1965). O autor Hawthorne cita como o primeiro barco o de 1975 criado por Alan T. Freeman, o mesmo pesquisador que criou o primeiro carro solar em 1980 (HAWTHORNE 1998).

A primeira embarcação de transporte de passageiro encontrada por gorter data de 1992 e se chama Solar Gajner. Percebe-se que o Solar Gajner já utiliza os populares motores de popa elétricos desenvolvidos a partir de 1975 para a pesca. Porém seus tamanhos são muito limitados. É uma embarcação para travessias realmente curtas.

Apenas em 1995 surgem barcos solares com comprimentos entre oito e 12 metros, tendo seu primeiro exemplar o Chlorophylle. Em 1997 surge o Sonneschein, uma embarcação solar muito citada na internet.

Um outro aspecto relevante de todas as embarcações é quanto às concepções, se são monocascos, catamarãs ou trimarãs. $40 \%$ das embarcações são monocascos, $42 \%$ catamarãs e $4 \%$ trimarãs(também foram excluídos dessa contagem os barcos de competição para se observar as características de outras funcionalidades).
Percebe-se que os conceitos de catamarã e monocascos encontraram mesma proporção nas embarcações solares e, apesar dos catamarãs terem maior área de convés, o que permite maior potência disponível. Os monocascos costumam ter menor resistência ao avanço, por isso são maioria nos barcos de competição.

Cabe comentar ainda que os barcos solares de pesquisa já realizaram a travessia do atlântico em 2007, com a embarcação Sun21. Em 2012 o Planet Solar completou a volta ao mundo, mostrando a capacidade dessa tecnologia.

Uma curta descrição dos motores, baterias, painéis e controladores possíveis de serem utilizados em barcos solares hoje (2012).

O barco solar pode ser definido como embarcação que capta energia do sol através de painéis fotovoltaicos, converte essa energia em energia elétrica, armazena ou não em uma bateria e, a partir de um motor elétrico, transforma essa energia elétrica em energia mecânica para locomover a embarcação. Portanto, conhecer os motores elétricos, as baterias e os painéis é fundamental para estudar a viabilidade dessas embarcações.

Existem inúmeros tipos de motores, baterias e painéis fotovoltaicos, e não se pretende descrever todos eles. Será feita uma breve descrição e comparação dos que vêm sendo mais utilizados.

\subsection{Motores}

Os motores elétricos são os responsáveis por transformar a energia elétrica em mecânica dentro da embarcação, sendo, portanto, os principais consumidores de energia nos barcos solares.

Como as pesquisas em barcos solares são em menor número, observa-se, primeiro, os resultados encontrados para os carros elétricos. O autor Chan (2002) lista algumas características importantes dos motores utilizados em carros elétricos. Os motores devem possuir:

1. Alta potência instantânea e alta densidade de potência.

2. Alto torque em velocidades baixas para partida e para subir ladeiras e alta potência para altas velocidades de cruzeiro.

3. Grande faixa de velocidades incluindo torque constante e potência constante em algumas regiões.

4. Respostas em alto torque.

5. Alta eficiência em uma larga faixa de velocidade e torques. 


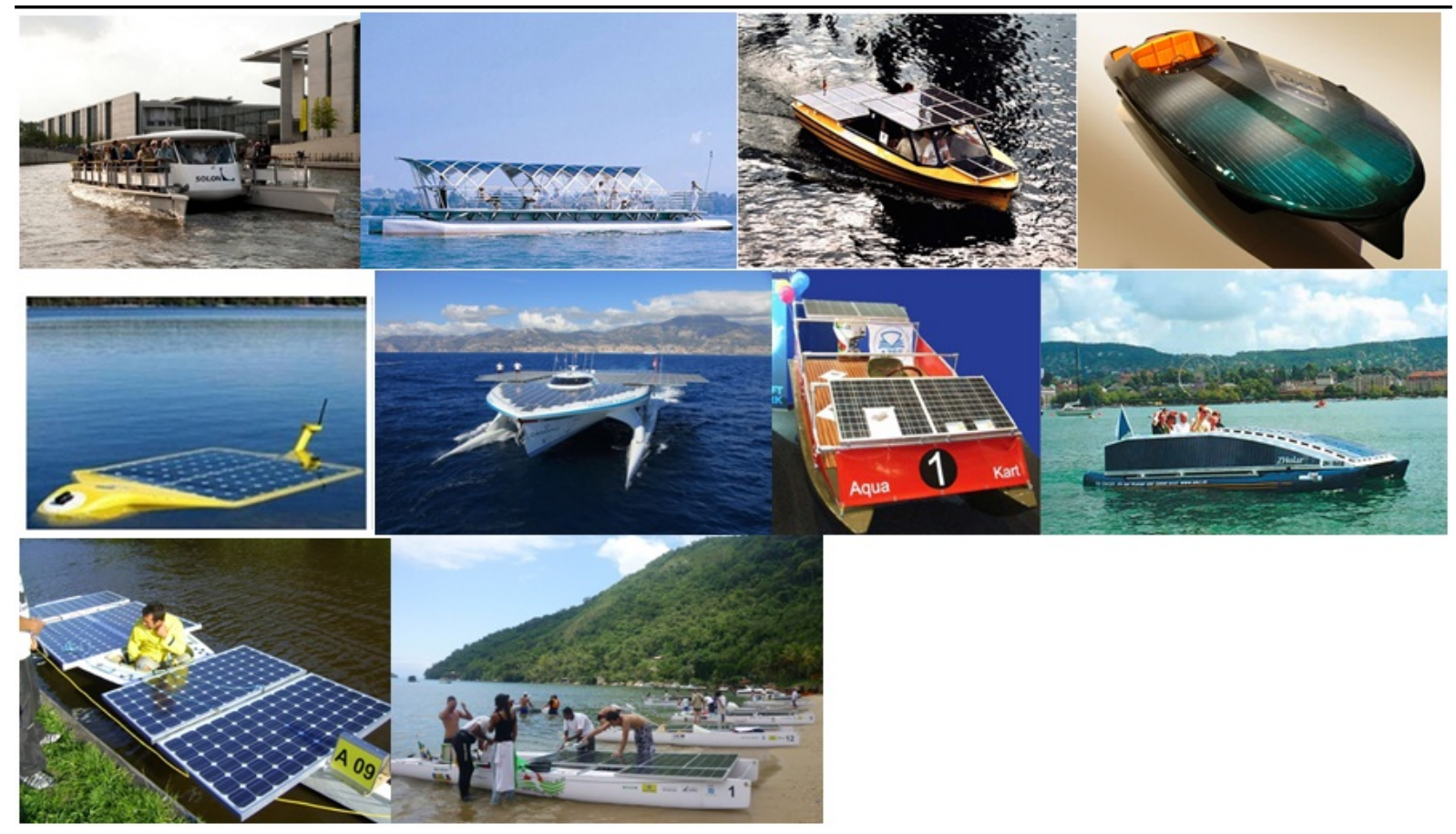

Figura 2: Da esquerda para a direita as embarcações: Sun Cat 58 e Ra 88 (transporte de passageiros) Krona e Czeers (uso privado), Hidroboat e Planet Solar (pesquisa), Aquakart e Zholar (recreação), Copacabana e barcos do desafio solar brasil ( competição).

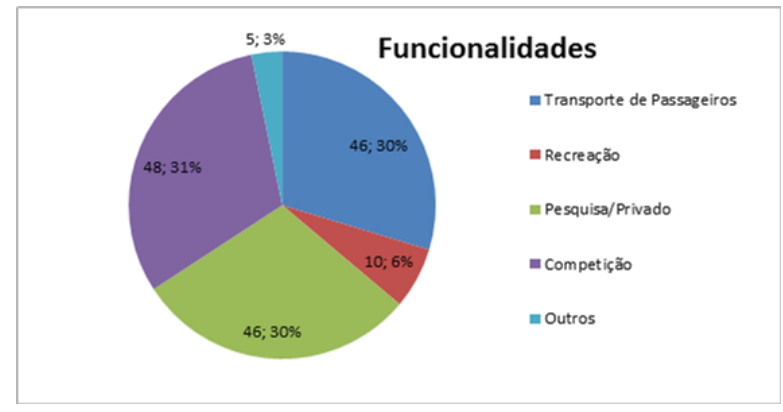

Figura 3: Gráfico das embarcações solares distribuídas por funcionalidade.

6. Alta eficiência para freio regenerativo.

7. Alta confiabilidade.

8. Custos razoáveis.

As demandas para barcos solares não são exatamente as mesmas, mas são semelhantes. Os barcos solares não precisam de aceleração, assim como os carros elétricos. Operam em faixas de velocidades mais restritas que os carros elétricos, que giram em torno da velocidade de cruzeiro. O torque inicial também deve ser alto para vencer a inércia no hélice, porém as potências mais altas serão as utilizadas em manobra e não em altas velocidades. Não utilizam freios regenerativos. Também necessitam de alta confiabilidade e custos razoáveis. Alta densidade de potência para redução do deslocamento e redução do volume interno são bemvindas. Porém, o percentual do peso do motor em comparação ao peso da embarcação é menor que do veiculo elétrico.

Observa-se os tipos de motores utilizados em carros elétricos listados também por Chan (2002). Destacase que os motores mais presentes são os de imã permanente (incluindo os CC e os CA), correspondendo a $36 \%$, seguidos pelos motores de indução e os de corrente continua ambos com $27 \%$.

Para analisar quais desses motores são mais interessantes para barcos solares, destaca-se o trabalho de (NANDA; KAR, 2006). Ao fim do artigo o autor compara os motores em termos de eficiência, confiabilidade, densidade de potência, maturidade da tecnologia e custos.

Esses dados foram resumidos na Tabela 2, sendo as qualidades são comparadas por numeração crescente de 1 a 3 . O numero 1 exibe os motores que possuem melhores características da respectiva qualidade e o numero 3 as piores características.

Chan (2002) faz ainda algumas considerações sobre os motores, afirmando que os motores $\mathrm{CC}$ foram os mais utilizados inicialmente por possuírem boas curvas 


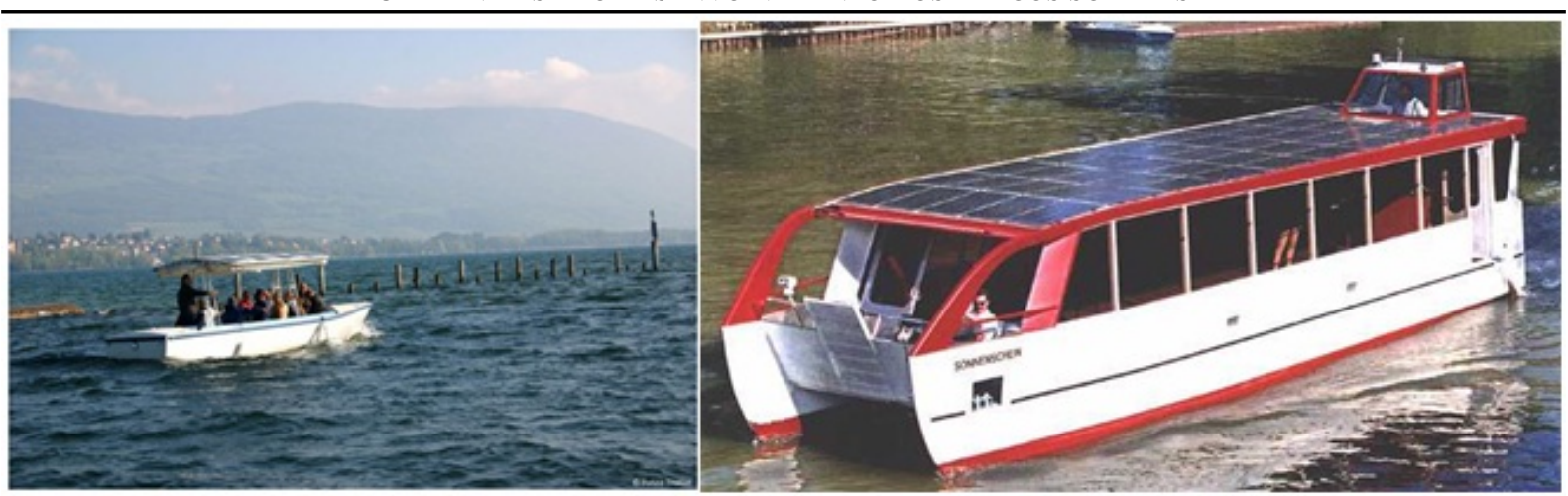

Figura 4: Da esquerda para a direita as embarcação Clorophylle1995 e Sonneschein 1997.

Tabela 2: Comparação dos motores elétricos.

\begin{tabular}{|c|c|c|c|c|}
\hline \multicolumn{5}{|c|}{ Comparação de motores elétricos (Kar) } \\
\hline Qualidades & Motor DC & Motor imã Perm. & Motor de indução & Chaveados \\
\hline Eficiência & 3 & 1 & 2 & 2 \\
\hline Confiabilidade & 3 & 2 & 1 & 1 \\
\hline Densidade de potência & 3 & 1 & 2 & 2 \\
\hline Maturidade da tecnologia & 1 & 2 & 1 & 2 \\
\hline Custos & 2 & 3 & 1 & 3 \\
\hline
\end{tabular}

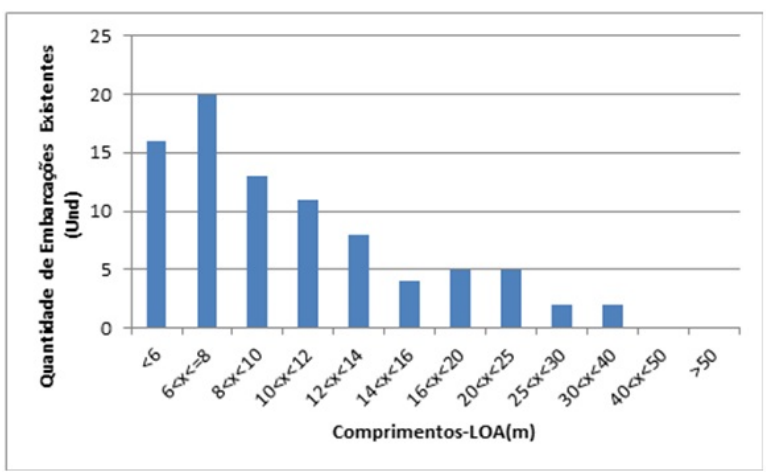

Figura 5: Gráfico quantidade de embarcações existentes x comprimentos, essa contagem exclui os barcos de competição.

de torque $\mathrm{x}$ rotação para veículos elétricos e pela facilidade de controle de velocidades. Possuem o inconveniente de terem comutadores e escovas que diminuem a eficiência e aumentam a manutenção.

Os motores de ímã permanente, segundo Chan (2002) possuem um peso menor, o que já havia sido destacado por Nanda e Kar (2006) quando se refere à densidade de potência desses motores serem mais altas. Como os ímãs permanentes saíram da carcaça para o rotor dos motores elétricos, melhoraram o resfriamento do motor e com isso a confiabilidade, pois reduzem os riscos de superaquecimento e aumentam a eficiên- cia pela não necessidade de magnetização dos eletroímãs. SegundoNanda e Kar (2006) os motores de ímãs permanentes podem ser CA ou CC. Os CA também são chamados motores de ímã permanente síncrono. Os de ímã permanente $\mathrm{CC}$ resultam virtualmente da inversão do estator com o rotor, segundo Chan (2002) eles também produzem torques mais altos.

Os motores elétricos de indução e os de imã permanente CA ou CC se apresentaram como soluções mais eficientes e possíveis para embarcações solares pois atenderam à principal demanda: alta eficiência. Obtiveram valores próximos de $90 \%$ e mantém essa eficiência em potências de $50 \%$ do seu valor máximo.

Nas pesquisas de Tim Gorter encontra-se a especificação de alguns motores elétricos utilizados nos barcos solares. Os dados possuem uma amostra pequena, pois a informação acerca do motor utilizado existe para apenas 15 das 111 embarcações catalogadas por ele.

Os motores da AGNI e os Fischer Panda, motores PM CC, configuram $66 \%$ das embarcações. O torqueedo e ETEK são motores PM CA. Juntando os dados de ambos temos que os motores de imã permanente (PM) correspondem a $80 \%$ dos motores utilizados. O motor da Krãutler e o da Siemens são motores de indução (IM). 


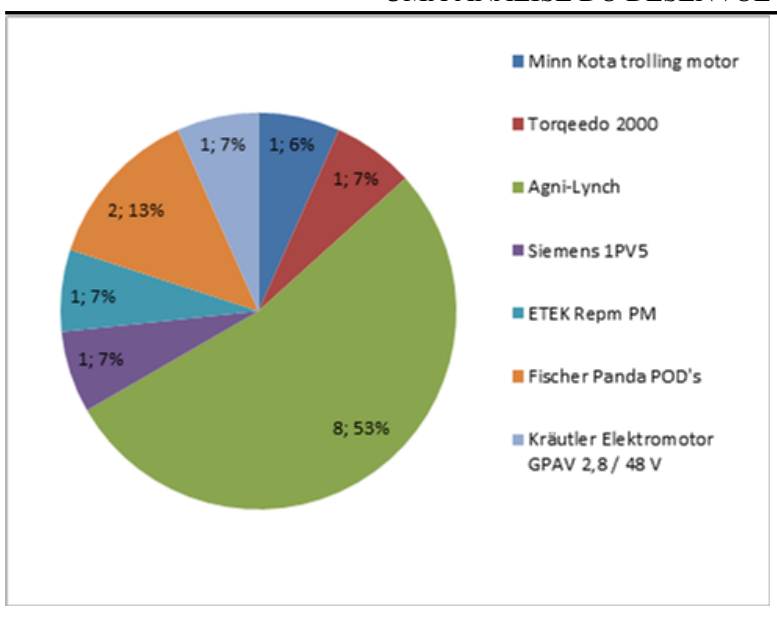

Figura 6: Motores elétricos encontrados nas embarcações solares.

\subsection{Baterias}

As baterias nos barcos solares têm a função de armazenar a energia elétrica, proveniente dos painéis fotovoltaicos, como energia química para utilizar posteriormente como energia elétrica.

As baterias são os maiores obstáculos para os veículos elétricos, segundo Chan (2002) as demandas de uma bateria para carros elétricos são:

1. Alta energia específica $(\mathrm{kWh} / \mathrm{Kg})$ e densidade de energia $(\mathrm{kWh} / \mathrm{litro})$.

2. Alta potência específica $(\mathrm{kW} / \mathrm{kg})$ e densidade de potência (kW/litro).

3. Alta velocidade de recarga e capacidade de descarga profunda.

4. Ciclos de vida longos e ciclos longos.

5. Alta taxa de descarga e alta eficiência de recarga.

6. Necessidade de pouca manutenção.

7. Reciclabilidade e baixos danos ao ambiente.

A alta energia especifica é um aspecto também interessante aos barcos solares, pois as baterias correspondem a uma parcela considerável do deslocamento da embarcação. O volume ocupado pela bateria não é um grande problema para a embarcação de transporte de passageiro ou de recreio. Nos barcos solares estudados não são necessárias velocidades de recargas altas. Ciclos de vida longos são importantes. Longos ciclos não são fundamentais pois, diferente dos carros elétricos, nos barcos solares os painéis fotovoltaicos é que possuem grande impacto sobre a autonomia. Alta taxa de descarga é um aspecto importante para suprir a demanda máxima de corrente do motor em manobra. Preocupação ambiental certamente é um ponto importante, e ser reciclável também. Porém, diferentemente dos carros elétricos, as baterias não parecem ser o grande obstáculo para o desenvolvimento dos barcos solares.

Nos dados de Tim Gorter foram descritas as baterias utilizadas por 22 embarcações do universo de 111 barcos solares levantados. As baterias de chumbo ácido são as mais utilizadas em barcos solares. O aspecto custo parece o fator determinante, associado à capacidade de entregar altas potências. Como visto na tabela 6 , possuem valores considerados bons, apesar de não serem os melhores.

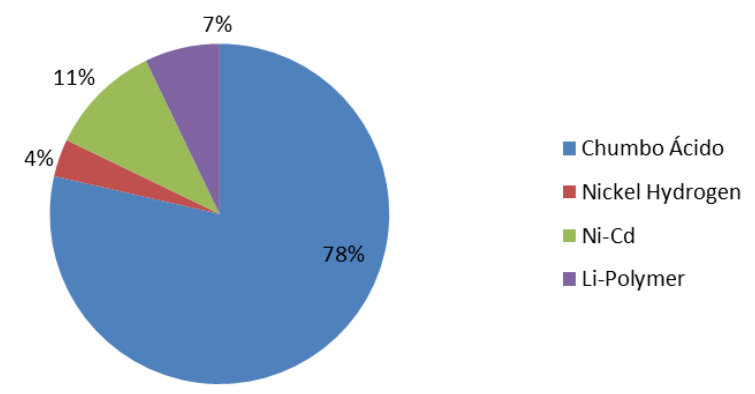

Figura 7: Baterias encontradas em barcos solares.

Os valores de eficiência de recarga utilizados por Boxwell (2011) são de 95\% de eficiência. Essa eficiência é um aspecto importantes nos barcos solares.

Outro ponto importante é que as baterias não podem ser recarregadas excessivamente, porém os painéis fotovoltaicos não têm controle do limite de carga e, caso os painéis não sejam desligados, as baterias vão ser levadas a voltagens extremamente altas, danificando-as. Por outro lado, a descarga de algumas baterias não pode chegar a voltagem muito baixa, o que também pode prejudicá-la. Para que esses equívocos não ocorram, são utilizados controladores de carga nos sistemas fotovoltaicos.

As baterias de chumbo ácido contribuem com 6 a $10 \%$ do deslocamento da embarcação para embarcações modeladas para barcos de transporte por Oliveira (2013). Esta modelagem garante uma autonomia de $2 \mathrm{~h}$ utilizando energia apenas na bateria.

\subsection{Painéis Fotovoltaicos}

As tecnologias, segundo Proença, são divididas em 3 gerações.

A primeira geração, que corresponde à tecnologia mais antiga, são as que produzem painéis de silício monocristalino e policristalino. Essa é a geração que pro- 
Tabela 3: Comparativa de baterias feita pelo pesquisador Chan.

\begin{tabular}{|c|c|c|c|c|c|}
\hline Baterias & $\begin{array}{c}\text { Energia } \\
\text { específica (Wh/kg) }\end{array}$ & $\begin{array}{c}\text { Densidade de } \\
\text { energia (Wh/litro) }\end{array}$ & $\begin{array}{c}\text { Potência } \\
\text { específica (W/kg) }\end{array}$ & $\begin{array}{c}\text { Ciclos de } \\
\text { vida (ciclos) }\end{array}$ & $\begin{array}{c}\text { Custos } \\
(\mathrm{US} \$ / \mathrm{kWh})\end{array}$ \\
\hline Chumbo-ácido & $30-45$ & $60-90$ & $200-300$ & $400-600$ & 150 \\
\hline Ni-Cd & $40-60$ & $60-110$ & $150-350$ & $600-1200$ & 300 \\
\hline Ni-MH & $60-70$ & $130-170$ & $150-300$ & 300 & $100-300$ \\
\hline Li.Polymer & 155 & 220 & 315 & 600 & NA \\
\hline Li-Ion & $90-130$ & $140-200$ & $250-450$ & $800-1200$ & $\begin{array}{c}\text { Maior } \\
\text { que } 200\end{array}$ \\
\hline
\end{tabular}

duz a maioria dos painéis fabricados comercialmente. Os painéis monocristalinos são mais eficientes, operando na faixa de $15 \%$ a $18 \%$ de eficiência. Os painéis policristalinos são um pouco menos eficientes, operando entre 12 e $15 \%$, porém possuem um custo de fabricação menor (PROENÇA, 2007).

As células de segunda geração pretendem reduzir o consumo do silício e utilizam a tecnologia do silício amorfo. Produzem painéis mais leves, porém menos eficientes, de 5 a $7 \%$ e com uma densidade de energia menor que s da primeira geração. Começam a ganhar espaço no mercado nos últimos anos e ganhar produção em escala (PROENÇA, 2007). Os painéis de filme fino possuem a vantagem prática de serem flexíveis, podendo cobrir superfícies curvas.

As células de terceira geração ainda estão sendo desenvolvidas em laboratório. Existem duas tecnologias: as células solares que são sensibilizadas por corante e possuem eficiência e custos baixos, e a tecnologia nomeada de junções múltiplas, como o Arseneto de Gálio, que possui um custo muito elevado e chega a $25 \%$ de eficiência. Esta tecnologia é hoje utilizada em satélites solares (PROENÇA, 2007).

Na modelagem feita no trabalho de Oliveira (2013) os painéis fotovoltaicos possuem uma massa que corresponde de 8 a $15 \%$ do deslocamento das embarcações. (GORTER; REINDERS, 2012), também comenta da importância da redução do peso nos painéis para melhoria de ganhos em eficiência de toda a embarcação pela redução da área molhada. Segundo os dados de Tim Gorter, foram identificadas as tecnologias dos painéis fotovoltaicos em 53 das 111 embarcações.

Percebe-se a predominância das tecnologias de primeira geração. $\mathrm{O}$ aspecto mais importante é a alta eficiência a custos acessíveis.

\section{CONTROLADORES}

\subsection{Controladores de velocidade do motor}

Os Conversores de frequência se desenvolveram substancialmente desde a década de 1960, quando o pri-

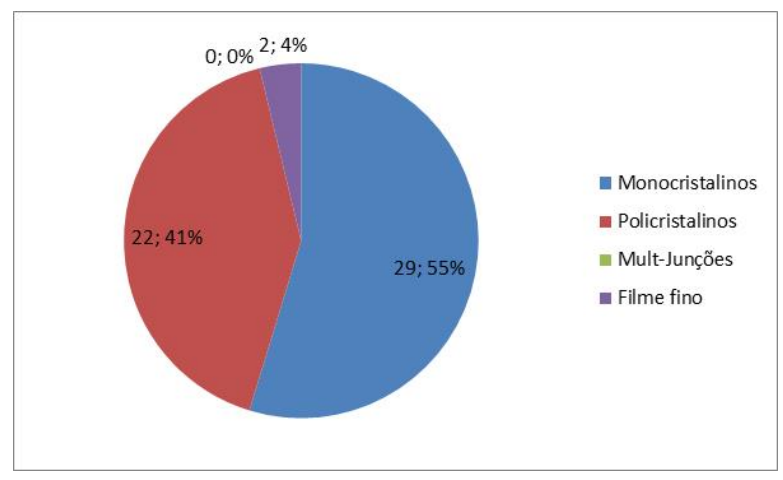

Figura 8: Gráfico dos painéis encontrados em embarcações solares.

meiro foi fabricado (PADILHA, apud CARUSO, 2007). Não se pretende discutir todos os tipos de sistema de filtragem e de chaveamento para os conversores. Existem várias variáveis eletrônicas por trás desses sistemas. Pretende-se observar a eficiência destes controladores.

\subsection{Controladores de Carga e MPPTs}

Os controladores e MPPTs possuem as mesmas características de uma instalação fotovoltaica.

Os controladores de carga têm a função de: monitorar as baterias para evitar a sobrecarga e o excesso de descarga. Para fazer isso medem a voltagem da bateria e desligam os painéis no caso de sobrecarga, ou desligam a carga quando a bateria apresentar valores muito baixos de voltagem; Desconectar os painéis para evitar a perda de corrente das baterias para os painéis durante a noite; Proteger contra sobrecorrente pela presença de fusíveis.

Os MPPTs muitas vezes acumulam a funções dos controladores de carga. Os MPPTs são constituídos por conversores CC-CC. Têm a função de operar um sistema com duas voltagens distintas. Isso pode ser interessante quando o ponto de máxima potência de um painel encontra-se a uma dada voltagem e ponto de potência da carga do motor ou o ponto de recarga ótima 
UMA ANÁLISE DO DESENVOLVIMENTO DOS BARCOS SOLARES

Tabela 4: Rendimento de motores e controladores - retirado do trabalho de Ramos (2010)

\begin{tabular}{|c|c|c|c|c|c|c|}
\hline & \multicolumn{3}{|c|}{ Rendimento (\%) } & \multicolumn{2}{|c|}{ Peso } & \multirow{2}{*}{ Custo } \\
\hline & Motor & Controlador & $\begin{array}{c}\text { Motor } \\
\mathrm{e} \\
\text { controlador }\end{array}$ & Motor & $\begin{array}{c}\text { Motor } \\
\mathrm{e} \\
\text { controlador }\end{array}$ & \\
\hline $\begin{array}{c}\text { Motor de } \\
\text { corrente contínua }\end{array}$ & 80 & 98 & 78 & 4 & 4,5 & 2 \\
\hline $\begin{array}{l}\text { Motor de } \\
\text { indução }\end{array}$ & 90 & 93 & 84 & 2 & 3 & 0,5 \\
\hline $\begin{array}{l}\text { Motor síncrono de } \\
\text { ímanes permanentes }\end{array}$ & 97 & 93 & 90 & 1 & 2 & 1 \\
\hline $\begin{array}{l}\text { Motor de relutância } \\
\text { comutado }\end{array}$ & 94 & 90 & 85 & 1,5 & 2,5 & 1,5 \\
\hline
\end{tabular}

da bateria encontra-se em outro. Caso não exista um MPPT o painel será forçado a operar com a voltagem da carga e uma parte da energia que poderia estar sendo fornecida pelo painel é perdida. Porém como comentado a alta eficiência das instalações fotovoltaicas de um barco solar não dispensam o uso de um MPPT.

\section{CONCLUSÃO}

Observa-se, portanto, que toda vez que surgem novas tecnologias, estas são rapidamente utilizadas para a locomoção de embarcações. Por exemplo, quando surgiram os primeiros motores elétricos e baterias, quando surgiram as máquinas a vapor e com o surgimento dos painéis solares, todos foram rapidamente testados nas embarcações.

Mudanças do domínio energético para movimentar as embarcações têm como "motor" o aspecto econômico: primeiro no custo de capital e no operacional, que se relacionam diretamente aos custos de aquisição e consumo das tecnologias. Segundo, se relaciona com aspectos técnicos difíceis de mensurar seu valor econômico direto, como a velocidade da embarcação e a manobrabilidade.

Atualmente existe uma frente que impulsiona a tecnologia por soluções não impactantes ambientalmente. Será que a transição do petróleo para as fontes alternativas de energia vai se tornar hegemônica? Parece que enquanto a energia solar não vencer os aspectos econômicos e técnicos, o petróleo seguirá dominando a locomoção das embarcações.

Outro aspecto a destacar neste trabalho é o desenvolvimento dos painéis fotovoltaicos. Apesar das possibilidades técnicas de implementação da tecnologia, esta só ganhou espaço no mercado quando os investimentos se deram para efetivar a redução de custos de fabricação, para que o produto pudesse ganhar um menor va- lor de venda. Será que esses ganhos de escala podem ser determinantes para que os barcos solares ganhem espaço?

Quando o custo de aquisição do petróleo se tornar exorbitante devido a sua escassez, outra fonte energética passará a dominar a locomoção dos veículos. Entretanto, será que o mundo esperará até o petróleo se extinguir, emitindo durante os próximos anos gases tóxicos na atmosfera? A província de Frysland, na Holanda, promete proibir embarcações com motores a combustão de transitar nos seus canais. Isso seria uma solução que transcende o aspecto econômico.

Outro exemplo de política que obteve resultados em mudanças que favorecem o meio ambiente sobre as decisões econômicas foi a implementação de cascos duplos em petroleiros em substituição aos cascos singelos. Nessa mudança o custo de fabricação dos navios aumentou expressivamente para reduzir os riscos de desastres ambientais, e hoje é uma politica inquestionável. Soma-se a essas experiências a proibição de circulação das motocicletas movidas por motor a combustão em algumas cidades chinesas em virtude do aumento da poluição. Com isso o crescimento do numero de bicicletas elétricas se tornou uma experiência marcante. Porém, mesmo sem decisões políticas e governamentais, a preocupação ambiental está levando os carros a terem soluções quase competitivas. E os barcos? Existe espaço para os barcos solares? A densidade de energia das baterias e dos painéis solares é muito menor que a dos combustíveis fósseis. Logo, parece que as políticas públicas vão ter papel fundamental nessa reposta.

Mesmo assim hoje eles são uma realidade, mesmo que com poucos exemplares. Os avanços nos ganhos de eficiência têm sido determinantes, Gorter (2015), comenta um ganho $15 \%$ de eficiência na competição de barcos movidos a energia solar em 2 anos. O aumento da eficiência pode levar a maiores velocidades. 
UMA ANÁLISE DO DESENVOLVIMENTO DOS BARCOS SOLARES

$\mathrm{O}$ estado da arte atual mostra que as tecnologias de projeto e construção de barcos, de motores elétricos e de inversores estão bastante maduras e apresentarão avanços incrementais, a não ser que os avanços em supercondutividade e em nanotecnologia produzam novos paradigmas. Em relação aos módulos fotovoltaicos, ainda há muitos desenvolvimentos a serem feitos, não somente em relação aos materiais a serem utilizados para aumentar sua eficiência, mas também aos processos que permitam a redução de seu custo e a uma fabricação sem agredir tanto o ambiente, como é o caso dos atuais módulos baseados em silício. De qualquer maneira, muitas pesquisas estão sendo realizadas mundo afora e certamente novos desenvolvimentos deverão surgir nos próximos anos.

\section{REFERÊNCIAS}

AMORIM, F. A. S. Uma pequena história das embarcações. Rio de Janeiro: Ed. da Escola de Engenharia UFRJ, 1997.

AQUINO, E. F. Filho de vapo, filho de vapo é !!! História, os navios da "Siderúrgica". 2012. Disponível em: <http://www.blogmercante.com/2012/10/ filho-de-vapo-filho-de-vapo-e-historia-os-navios/> Acesso em: 29 jan. 2012.

BOXWELL, M. Solar Electricity Handbook. United Kingdon: Greenstream Publishing, 2011.

CARUSO, J. M. Controle de velocidade de um MIT tracionando um veículo elétrico. Dissertação (Mestrado em Automação e Robótica) - Universidade de Taubaté, Taubaté, São Paulo, 2007.

CHAGAS, M. W. P. Novas Tecnologias para Avaliação de Baterias. Dissertação (Mestrado em desenvolvimento de tecnologia) - Instituto de Engenharia do Paraná, Curitiba. Paraná, 2007.

CHAN, C. The state of the art of electric and hybrid vehicles. Proceedings of the IEEE, IEEE, v. 90, n. 2, p. 247-275, 2002.

DATHEIN, R. Inovação e Revoluções Industriais: uma apresentação das mudanças tecnológicas determinantes nos séculos XVIII e XIX. 2003. Disponível em: <www.ufrgs.br/decon/publionline/ textosprofessores/ricardo/022003.doc > Acesso em: 26 jan. 2013.

GORTER, T. Design considerations of a solar racing boat: Propeller design parameters as a result of $\mathrm{pv}$ system power. Energy Procedia, Elsevier, v. 75, p. 1901-1906, 2015.
GORTER, T.; REINDERS, A. A comparison of 15 polymers for application in photovoltaic modules in pv-powered boats. Applied energy, Elsevier, v. 92, p. 286-297, 2012.

GORTER, T.; VOERMAN, E.-J.; JOORE, P.; REINDERS, A.; HOUTEN, F. V. Pv-boats: design issues in the realization of pv powered boats. In: DELFT UNIVERSITY OF TECHNOLOGY; THE HAGUE UNIVERSITY OF APPLIED SCIENCES; TNO. Knowledge Collaboration \& Learning for Sustainable Innovation: 14th European Roundtable on Sustainable Consumption and Production (ERSCP) conference and the 6th Environmental Management for Sustainable Universities (EMSU) conference, October 25-29. Delft, Netherlands, 2010.

HAWTHORNE, E. 100 years of Going With the Current. 1998. Disponível em: <http: //www.electric-boat-association.org.uk/history.htm> Acesso em: 26 jan. 2013.

NANDA, G.; KAR, N. C. A survey and comparison of characteristics of motor drives used in electric vehicles. In: IEEE. Electrical and Computer Engineering, 2006. CCECE'06. Canadian Conference on. Canadá, 2006. p. 811-814.

NISENBAUM, M. A. Pilhas e Baterias. 2008. Disponível em: <http://web.ccead.puc-rio.br/ condigital/mvsl/Sala\%20de\%20Leitura/conteudos/SL_ pilhas_e_baterias.pdf $>$ Acesso em: 26 jan. 2013.

OLIVEIRA, M. A. N. de. ANÁLISE DA VIABILIDADE DE EMBARCAÇÕES SOLARES PARA TRANSPORTE DE PASSAGEIROS. Tese (Doutorado) - Universidade Federal do Rio de Janeiro, 2013.

POMILIO, J. A. Uma breve história da eletricidade industrial e da eletrônica de potência. 2011.

Disponível em: <http://www.dsce.fee.unicamp.br/ antenor/pdffiles/eltpot/historia.pdf> Acesso em: 26 jan. 2013.

PROENÇA, E. D. R. B. A Energia Solar Fotovoltaica em Portuga - estado da arte e perspectivas de desenvolvimento. Dissertação (Mestrado) Universidade de Lisboa, Lisboa, Portugal, 2007.

RAMOS, T. M. S. Sistema de tração em um VEC (Veículo Elétrico de Competição). Dissertação (Mestrado) — Faculdade de Engenharia da Universidade do Porto, 2010.

SAMPAIO, M. R. O ônibus etano-elétrico, transporte sustentável-alternativas para o ônibus urbano. Rio de Janeiro, 2006. 
VALLÊRA, A. M.; BRITO, M. C. Meio século de história fotovoltaica. Gazeta da física, v. 29, n. 1, p. 10-15, 2006.

VARELLA, C. A. A. "Histórico e desenvolvimento dos motores de combustão interna", notas de aula da disciplina de motores e tratores. 1995. Disponível em: <Http://www.ufrrj.br/institutos/it/deng/varella/ Downloads/IT154_motores_e_tratores/Aulas/ historico_e_desenvolvimento_dos_motores.pdf> Acesso em: 12 fev. 2016.

WALSH, J. Solar boat: Army evaluators record a plus for novel craft. Science (New York, NY), v. 147, n. 3665 , p. $1559,1965$. 